\title{
A caminho do Araguaia: três trajetórias militantes
}

\author{
Rafaela N. Pannain*
}

\section{Resumo}

Este artigo analisa as trajetórias militantes de Maurício Grabois, Elza Monnerat e João Amazonas, membros do Partido Comunista do Brasil enviados à região do Araguaia para organizar um movimento armado contra a ditadura civil-militar instaurada com o golpe de 1964. O objetivo é apreender o processo de construção do sentido de um engajamento político que implicava em alto risco para os militantes. Em diálogo com a literatura sobre movimentos sociais, são analisadas a disponibilidade biográfica dos agentes, sua identificação ideológica com o movimento, suas redes sociais e o impacto da repressão estatal. Mais velhos do que a média da esquerda armada do período, esses militantes compartilhavam uma longa trajetória no partido comunista, durante a qual as predisposições criadas com a socialização militante foram corroboradas por mudanças no contexto político nacional e internacional, experiências coletivas e individuais de perseguição, clandestinidade, prisão e pelas mudanças ocorridas no interior da sua organização.

Palavras-chave: trajetória militante, ditadura civil-militar, Guerrilha do Araguaia, comunismo.

* Centro Brasileiro de Análise e Planejamento, São Paulo, SP, Brasil.

$\checkmark$ Esta pesquisa foi realizada com financiamento da Fundação de Amparo Pesquisa do Estado de São Paulo (Fapesp), processos no 2015/21242-8 e no 2017/12061-5. Agradeço a Angela Alonso, Sérgio Costa e Caio Vasconcellos pelos comentários às versões preliminares e aos pareceristas anônimos da revista Sociologias. 


\section{On the way to Araguaia: three militant paths}

\section{Abstract}

This article presents the militant trajectories of Maurício Grabois, Elza Monnerat, and João Amazonas, members of the Communist Party of Brazil sent to the Araguaia region to organize an armed movement against the Brazilian civil-military dictatorship established with the 1964 coup. I aim to shed light on the construction of a highrisk militant engagement. Drawing on the literature on social movements, these trajectories are presented observing the agents' biographical availability, their ideological identification to the movement, their social networks, and the role of state repression. These militants were older than most Brazilians who joined the armed left. During their long paths as militants for the communist party, the predisposition created by their militant socialization was corroborated by national and international political events, the collective and personal experiences of persecution, prison, living underground, and the changes in their organization.

Keywords: militant paths, civil-military dictatorship, Araguaia guerrilla movement, communism.

\section{Introdução}

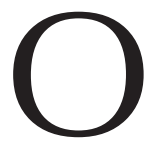

rganizada pelo Partido Comunista do Brasil (PCdoB), a Guerrilha do Araguaia foi um movimento armado contra a ditadura civilmilitar inaugurada pelo golpe de 1964. Entre 1966, quando o primeiro militante chegou à região do Bico do Papagaio, e abril de 1972, momento em que é lançada a ofensiva militar contra os guerrilheiros, 78 militantes comunistas foram enviados pelo partido à região onde seria formada a guerrilha. Já a repressão contou com “cerca de 7.200 homens, entre militares, policiais e mateiros" (Morais; Silva, 2011, p. 236).

O empenho da ditadura na eliminação do movimento e de guerrilheiros e guerrilheiras - em grande parte, assassinados sob custódia dos militares - indica a preocupação dos defensores do regime com o movimento organizado pelo PCdoB na Amazônia brasileira e a importância desse evento político. Com efeito, a guerrilha rural estava no horizonte de grande 
parte das organizações que recorreram ao enfrentamento armado contra a ditadura. Para as diferentes organizações que compunham a "esquerda armada", a guerrilha urbana deveria financiar uma guerrilha rural, esta sim com maiores possibilidades de sucesso naquele contexto (Ridenti, 2010). Com uma estratégia diferente, já que optara por não criar núcleos guerrilheiros urbanos, o PCdoB foi aquele que chegaria mais perto da criação de um movimento armado no campo no Brasil.

Em diálogo com a literatura sobre movimentos sociais, reconstruo neste artigo três trajetórias de militantes do PCdoB engajados na preparação da Guerrilha do Araguaia. O objetivo é apreender o processo de construção do sentido de um engajamento político que implicava em alto risco para os militantes (McAdam, 1986). Não pretendo revisitar a discussão acerca dos eventuais erros e acertos contidos nas leituras de organizações da esquerda brasileira que defendiam a viabilidade da luta armada naquele contexto (Gorender, 1987; Reis Filho, 1990), mas abordar as condições que tornaram possível o trabalho de construção de identidades militantes, de interpretação do contexto político e de identificação com uma forma específica de ação política, qual seja, a luta armada contra uma ditadura.

Partindo de trabalhos sobre engajamento de alto risco, busco lançar nova luz sobre o engajamento de militantes nas guerrilhas contra a ditadura civil-militar brasileira. Militantes de longa data, Elza Monnerat tinha 54 anos, Maurício Grabois e João Amazonas, 55, quando chegaram à região da guerrilha. A escolha de agentes com uma longa história de militância comunista é de especial interesse, pois trata de um tipo de trajetória pouco presente no imaginário social e nas pesquisas sobre aqueles que enfrentaram a ditadura. Além de iluminarem a existência de diferentes trajetórias geracionais, essas histórias de vida indicam distintos contextos históricos e eventos políticos que contribuíram para a construção do sentido da luta armada, visto que trajetórias militantes são atravessadas e construídas em diálogo com as histórias nacionais, da sua organização e de eventos ocorridos em diferentes partes do mundo. 
A primeira parte deste artigo aborda, então, o debate sobre carreiras e trajetórias militantes presente na literatura sobre movimentos sociais, com especial interesse para aspectos destacados em estudos acerca de movimentos que podem ser considerados de alto risco. Em seguida, concentro-me no objetivo principal do artigo, a reconstrução das trajetórias militantes atenta ao debate proposto pela literatura apresentada. Finalmente, destaco características comuns das trajetórias de longa militância no comunismo que levaram ao Araguaia, apontando algumas especificidades presentes na trajetória de Elza Monnerat, única mulher dentre os seis militantes da "primeira geração" do PCdoB deslocada para a região da guerrilha.

\section{Trajetórias e carreiras militantes}

Adoto aqui o termo trajetória militante em diálogo com a noção de carreira à qual recorrem pesquisadores dos movimentos sociais para explicar o engajamento e o desengajamento de ativistas. O conceito de carreira "nos permite focar no processo e na dialética permanente entre história individual, instituições sociais e, de forma mais geral, contexto", explica Fillieule (2010, p. 4). ${ }^{1}$ Por um lado, adota-se uma perspectiva diacrônica que leva em conta as mudanças nas identidades e seus mecanismos sociais e, por outro, a partir de uma perspectiva sincrônica, são analisados os mundos e submundos sociais múltiplos nos quais os atores estão inseridos. Fillieule explica:

Quando aplicada ao engajamento político, a noção de carreira nos permite entender como, em cada estágio biográfico, as atitudes e comportamentos dos ativistas são determinados por atitudes e comportamentos anteriores, que condicionam o leque de possibilidades futuras, situando, dessa forma, o engajamento no ciclo de vida completo (Fillieule, 2010, p. 11).

Com uma leitura similar, Agrikoliansky (2001) define carreiras como itinerários objetivos que se traduzem em subjetivações que guiam a ação. A trajetória militante não deve ser considerada como "o fruto de uma

\footnotetext{
1 Todas as traduções dos textos originais foram feitas por mim.
} 
estratégia preestabelecida, mas como o resultado de uma série de ajustes" (Agrikoliansky, p. 34), e o seu sentido deve ser entendido dentro das possibilidades de trajetórias existentes no campo. A propensão a determinado engajamento (ou tipo de engajamento) indica uma trajetória singular ao longo da qual se construiu progressivamente a justificativa desse tipo de ação.

Embora apresente uma definição de carreira militante, Agrikoliansky recorre de forma similar ao termo "trajetória". O uso combinado dos dois termos é reivindicado por Julie Pagis (2009), explicitamente, e implicitamente por Fillieule et al. (2018), em trabalhos que observam os eventos de 1968 na França a partir de sua inserção no tempo longo das trajetórias individuais. Usar histórias de vida implica ter em conta "o desencadeamento dos processos observados (temporalidade das idades, dos contextos e das arenas de interação) e interessar-se pela multiplicidade das esferas da vida (trabalho, família, atividades sociais, militância etc.) de forma interdependente", advertem Fillieule et al. (2018, p. 26).

Pagis adota o termo "trajetória" ao se debruçar nos "encontros entre habitus e evento", atenta à "sociogênese de disposições contestadoras e das modalidades e configurações sócio-históricas nas quais elas se atualizam", ao papel do evento como "elemento fundador" de uma socialização durável e às consequências da militância na biografia dos atores (Pagis, 2009, p. 31). Para entender a militância, a autora defende a necessidade de se ter em conta os "efeitos do ciclo de vida" (ligados à idade e à posição nesse ciclo), os "efeitos de coorte" (contexto socio-histórico e cultural comum no qual crescem agentes com uma mesma idade) e os "efeitos de período" (incidentes de uma conjuntura ou um evento histórico). Esses efeitos aliados criam uma unidade geracional, explica.

Ao lançar luz sobre a existência de diferentes famílias de trajetórias que participam dos eventos, sem compartilhar "nem os mesmos referentes políticos, teóricos e intelectuais, nem a mesma 'memória coletiva', nem os mesmos interesses e reivindicações políticas", Pagis (2009, p. 35) nos ajuda a explicar a especificidade de trajetórias militantes com uma longa 
militância no comunismo, quando comparadas àquelas de jovens militantes da esquerda armada durante a ditadura civil-militar brasileira.

Em diálogo com Viterna (2006), Bosi e Della Porta (2012) e seus tipos ideais de caminhos para o engajamento em organizações armadas, retomo na reconstrução das trajetórias dos militantes do PCdoB diferentes variáveis avançadas pela literatura sobre engajamento de alto risco, onde os riscos são entendidos como "perigos antecipados - seja legal, social, físico, financeiro etc. - do engajamento em um tipo particular de atividade" (McAdam, 1986, p. 67). Deste modo, a análise estará atenta à influência da disponibilidade biográfica dos agentes, definida como "a ausência de restrições que podem aumentar os custos e os riscos da participação no movimento, como trabalho a tempo integral, casamento e responsabilidades familiares" (McAdam, 1986, p. 70).

Desde que McAdam (1986) elaborou a hipótese da centralidade da disponibilidade biográfica para a passagem de um ativismo de baixo risco a outro de alto risco, houve um profícuo debate em torno dessa hipótese. Aqui, a contribuição de Viterna (2006) é de especial interesse. Seus achados corroboram aqueles de McAdam acerca do impacto das barreiras biográficas para o ativismo de alto risco e alto custo, ressaltando, contudo, a possibilidade de sua superação. A autora indica como a análise da disponibilidade biográfica deve vir associada ao papel do contexto político, especialmente da repressão estatal, e à inserção em redes sociais.

A atenção dada às redes sociais por Viterna (2006) está igualmente presente em uma vasta bibliografia dedicada ao engajamento de alto risco. É o caso do estudo de Della Porta acerca dos movimentos da esquerda libertária na Itália e na Alemanha, nas décadas de 1960 e 1970, sobre os quais a autora afirma que "a escolha de se engajar em uma organização radical era raramente uma escolha individual" (Della Porta, 1995, p. 167).

O impacto das redes organizacionais, das redes pessoais e dos laços fortes entre os agentes para este tipo de engajamento e sua manutenção aparece com destaque em McAdam (1986), Della Porta (1995) e Salgado (2015). McAdam e Paulsen (1993) argumentam que o processo de recrutamento 
deve criar uma relação positiva entre a organização e a identidade saliente do indivíduo. ${ }^{2}$ Por um lado, essa associação deve ser confirmada pelas pessoas com quem o indivíduo mantém laços que sustentam a identidade em questão, e, por outro, não deve haver forte oposição de pessoas às quais suas outras identidades salientes estão relacionadas. Assim, além da existência de um laço forte prévio com outros voluntários - apontada por McAdam (1986) como melhor indicador para o ativismo de alto risco McAdam e Paulsen (1993) incluem novos laços na análise, ao considerar a oposição ou apoio recebido por militantes de seus pais e amigos, grupos religiosos e seus representantes, e organizações de direitos civis.

A necessidade de se ter em conta a relação entre diferentes redes foi igualmente apontada por Gould (1991). Ao focar na relação entre os laços sociais criados na organização e as redes preexistentes, o autor sublinha a importância dos laços preexistentes para o recrutamento - como apresentado por McAdam (1986) e Della Porta (1995) - mas também para a manutenção da mobilização. Em Gould, como em Della Porta, a solidariedade como produto dos laços sociais é um elemento-chave. Já Bosi e Della Porta (2012) chamam a atenção para o fato de os efeitos das redes sociais variarem em função do tipo de rede e sua relação com as motivações dos agentes e o momento do engajamento, lançando luz sobre dois fatores centrais na reconstituição das trajetórias dos militantes do PCdoB apresentadas neste artigo, a saber, a construção do sentido da luta armada para os agentes e o impacto da repressão política nas suas militâncias.

Se Fillieule et al. (2018) advertem sobre a necessidade de estudos de trajetórias militantes levarem a sério as forças das ideologias dominantes, McAdam (1986) e Della Porta (1995) afirmam que uma forte identificação

${ }^{2} \mathrm{O}$ conceito de identity salience, emprestado de Sheldon Stryker, indica que "a saliência de uma identidade particular é uma atribuição do comprometimento do indivíduo com ela" (McAdam; Paulsen, 1993, p. 646). 
pessoal com o movimento é fundamental para o engajamento de alto risco. ${ }^{3}$ E a construção do sentido da mobilização para os agentes tem relação direta com o papel das redes sociais na sua socialização política, seja ela primária - ou seja, no núcleo familiar - ou por meio de laços pessoais e organizacionais que o agente tecerá ao longo da vida. A socialização ideológica é fundamental na passagem do ativismo de baixo risco àquele de alto risco. Nesse processo, novas identidades coletivas são elaboradas e uma identidade militante é construída.

A repressão estatal tem destaque nos estudos sobre engajamento de alto risco. Para Viterna (2006), por exemplo, ela aparece como uma explicação central para o ingresso na guerrilha salvadorenha em duas das três trajetórias típicas observadas, enquanto na terceira, embora as futuras militantes se encontrassem em um local seguro, algumas explicam seu engajamento como uma resposta ao assassinato de algum parente pelas forças do governo. Na análise de Della Porta (1995), a radicalização da militância na Alemanha e na Itália e seu caminho para a clandestinidade são explicados, em grande medida, como resultado da repressão estatal a diferentes organizações sociais legais e seus militantes, criminalizando o protesto.

Como veremos nas trajetórias apresentadas a seguir, para além do impacto objetivo da repressão, a interpretação que os agentes fazem de eventos repressivos estatais é fortemente influenciada por sua socialização prévia (Bosi; Della Porta, 2012) e por uma interpretação coletiva elaborada pelas organizações sociais (Almeida, 2005).

\footnotetext{
3 Para movimentos de massa, como movimento guerrilheiro em El Salvador estudado por Viterna (2006), em fases avançadas da luta armada, quando essa já envolve uma parte importante da população do país, é possível observar, como demonstra a autora, um engajamento que independe da identificação com o movimento e que responde a uma imposição do contexto político.
} 


\section{A longa militância comunista}

\section{O partido, a Aliança Nacional Libertadora e os governos de Getúlio Vargas}

Maurício Grabois e Elza Monnerat estiveram entre os primeiros militantes do Partido Comunista do Brasil a se dirigirem à região do Bico do Papagaio, em dezembro de 1967. Em julho do ano seguinte, chegou João Amazonas para compor a comissão militar do movimento armado, ao lado de Angelo Arroyo e Grabois, o comandante.

Maurício Grabois cresceu em Salvador, seus pais ucranianos imigraram para o Brasil no início do século XX, fugindo da perseguição antissemita. ${ }^{4} \mathrm{Em}$ 1932, ainda jovem, Grabois se filiou ao partido comunista. É provável que a aproximação com o partido se tenha dado durante sua breve passagem pela Escola Militar de Realengo, em 1931, tendo em vista a influência dos comunistas em determinados setores militares naquele momento. Expulso da escola militar, passou a se dedicar exclusivamente às atividades do partido, assumindo em pouco tempo a direção do setor de comunicação da Federação da Juventude Comunista.

Um ano após sua entrada no partido, Grabois foi detido em um protesto; seria a primeira de muitas prisões. E, em 1934, quando conflitos internos levaram à reorganização do partido, o jovem militante assumiu seu primeiro cargo de responsabilidade ao ser eleito para direção estadual no Rio de Janeiro.

João Amazonas nasceu em 1912, em Belém, em uma numerosa família sem tradição de militância. ${ }^{5}$ Amazonas começou a trabalhar aos dez anos

${ }^{4}$ Para a reconstituição da trajetória de Maurício Grabois foram consultadas as biografias escritas por Victória Lavínia Grabois (2012), filha do militante, e por Osvaldo Bertolino (2012), pesquisador da Fundação Maurício Grabois, do PCdoB, além de documentos escritos pelo próprio Grabois e informações de Victória Grabois em entrevista realizada com a autora em outubro de 2016, no Rio de Janeiro.

${ }^{5}$ A reconstituição da trajetória de João Amazonas se baseia principalmente na biografia do militante comunista escrita por Augusto Buonicore (2012). Foram igualmente consultados documentos redigidos por Amazonas. 
de idade e, estudando à noite, formou-se em contabilidade. Com a morte dos pais, as irmãs mais velhas assumiram os cuidados dos pequenos, e Amazonas, o filho homem mais velho e então com dezessete anos, tornouse responsável pela manutenção financeira da família. Trabalharia por nove anos em um cargo administrativo na Fábrica Palmeira, a mesma empresa na qual seu pai trabalhara como padeiro.

A notícia sobre um encontro da Aliança Nacional Libertadora (ANL), publicada em um jornal, levou Amazonas até o PCB, em 1935. A ANL nascera naquele ano a partir da união de forças antifascistas, dentre elas o partido comunista. Amazonas montaria uma célula do PCB na Fábrica Palmeira e, mais tarde, um sindicato. Sua militância o levou à prisão pela primeira vez já em 1935 e, naquele mesmo ano, passou a compor a direção estadual do PCB no Pará.

O governo Vargas perseguia comunistas, aliancistas e antifascistas (Prestes, 2005). Com a declaração da ilegalidade da ANL, apenas três meses após a sua fundação, os comunistas se radicalizaram. No PCB, acreditava-se ser possível desencadear, ao lado dos levantes militares, diferentes focos guerrilheiros rurais que derrubariam Getúlio Vargas (Santos, 2009, p. 411). A tentativa de insurreição em novembro de 1935, comandada pela ANL, foi reprimida, e os comunistas perseguidos. O PCB foi cassado e militantes comunistas torturados. Amazonas foi detido e passaria mais de um ano na prisão até ser julgado e absolvido por falta de provas. A partir da derrota da ANL, Maurício Grabois viveria clandestinamente pelo resto de sua vida, com a exceção dos breves períodos de 1945 a 1947 e 1956 a 1964.

A violência contra os comunistas se intensificou com a ditadura do Estado Novo. Como muitos militantes, Grabois foi preso em 1939 e, de novo, em 1941, quando passou 15 meses encarcerado. No intervalo entre as prisões, trabalhou na empresa Panair do Brasil, emprego que deixaria uma vez convocado para reorganizar o jornal do partido A Classe Operária, em São Paulo. Em 1941, foi enviado pelo PCB para Belo Horizonte.

João Amazonas também foi empurrado para a clandestinidade. Responsável por editar material do partido, foi preso em setembro de 1940. 
Em agosto do ano seguinte, fugiu da prisão, chegando ao Rio de Janeiro depois de um longo trajeto pelo interior do país. Amazonas encontrou trabalho na capital como auxiliar de contabilidade para, em seguida, também ser enviado a Belo Horizonte para ajudar na reorganização local do partido. Em Minas Gerais, trabalhou em uma fábrica de móveis e se filiou ao Sindicado dos Comerciários. Em 1943, seria enviado pelo PCB para o Rio Grande do Sul, Paraná, Santa Catarina e Bahia.

Ao sair da prisão, Grabois participou da reorganização nacional do PCB ao lado de Amazonas, Pedro Pomar e outros. No contexto da Segunda Guerra Mundial, defendiam a união nacional em torno de Vargas. Na Il Conferência Nacional do PCB, realizada em agosto de 1943, conhecida como Conferência da Mantiqueira, a corrente de Grabois e Amazonas sairia vitoriosa, e eles assumiriam os cargos de secretário de divulgação e propaganda da Comissão Executiva do Partido e de secretário sindical, respectivamente.

Grabois se tornou também diretor da revista mensal Continental. Com efeito, ao longo de toda sua trajetória militante, Grabois se dedicou à escrita de artigos e à edição de periódicos de circulação entre comunistas; fato que o colocou no centro dos debates sobre a orientação política e os programas do partido. Em 1943, nasceu a primeira filha de Grabois, Victória. No ano seguinte, Grabois seria preso em duas ocasiões.

\section{A legalidade e a Constituinte}

Em 1945, com o fim da ditadura do Estado Novo, o Partido Comunista foi legalizado e, nas eleições de dezembro, elegeu quatorze deputados federais e Prestes como senador. Elza Monnerat entrou no PCB naquele ano, quando milhares de pessoas se filiaram ao partido. Ela crescera no interior do Estado do Rio de Janeiro, filha de um pequeno produtor. ${ }^{6}$ Como filha mulher mais velha, era responsável por ajudar nas atividades da casa e, mais tarde, passou a contribuir com seu salário de professora para a

${ }^{6}$ As informações aqui apresentadas sobre Elza Monnerat estão em sua biografia, escrita por Verônica Bercht (2013), que inclui o diário que Elza escreveu durante os anos em que esteve presa (1976-1979). 
manutenção da família, cuja renda foi fortemente afetada pela morte do pai. Mudou-se para Niterói para terminar os estudos, dava aulas de manhã e à tarde e, à noite, estudava.

Em 1938, Monnerat foi aprovada no concurso público para o Instituto de Aposentadoria e Pensão dos Industriários. O novo trabalho Ihe proporcionaria uma situação financeira mais cômoda e um espaço para atuação política. Naquele momento, considerava-se "prestista". Foi na campanha pela anistia aos presos políticos do Estado Novo, em 1945, que conheceu os militantes que a levaram ao partido. Monnerat foi então uma das responsáveis por organizar a célula comunista em seu trabalho. Era membro do Comitê de Mulheres Pró-Democracia e, nas eleições de dezembro de 1945, participou das campanhas de Prestes, Grabois e Amazonas. Não obstante seu grande engajamento, a militante não falava nas reuniões do partido porque, segunda ela, "tinha um medo doido de dizer qualquer coisa que parecesse trotskista"; avaliava, assim, ter direito a voto, mas não a voz (Bercht, 2013, p. 77).

Amazonas e Grabois foram eleitos pelo PCB em 1945, e o último se tornou líder da bancada comunista na Constituinte. Aquele foi também o ano do nascimento de André Grabois, segundo filho de Maurício e Alzira que, em função da perseguição política sofrida, seriam privados do convívio diário com seus filhos durante grande parte de suas vidas.

\section{A repressão estatal e a mudança na estratégia do partido}

O PCB crescia quando foram cassados, em 1947, seu registro e, em 1948, os mandatos de seus representantes no Congresso Nacional. O Presidente da República era Eurico Gaspar Dutra. Em discurso na Câmara de Deputados, Grabois (1948) denunciava "a luta descarada e direta contra a democracia", liderada pelo "ditador, que podemos qualificar de fascista, homem idêntico a Morinigo, Trujillo e Franco".

No dia seguinte à cassação, Grabois foi preso. Ao ser liberado, entrou mais uma vez na clandestinidade. O ex-deputado continuou escrevendo na 
imprensa comunista. Ao tratar das limitações do trabalho do partido com as massas no campo, Grabois indicava o desconhecimento, por parte dos comunistas, dos problemas do campesinato, e a ausência de quadros do partido entre os camponeses "adaptando-se aos seus costumes e hábitos, adquirindo a sua confiança, falando-lhes a sua linguagem, sentindo aquilo que mais lhes interessa, levantando suas reivindicações imediatas, organizando-os e levando-os para as lutas" (Grabois, 1949). Esse diagnóstico estaria, anos mais tarde, no centro da estratégia do movimento guerrilheiro comandado por Grabois no norte do Brasil.

As décadas de 1940 e 1950 representaram um período relevante de organização do campesinato, com a formação das ligas camponesas e a radicalização da luta pela terra em diferentes regiões do país. Nesse período, o PCB participou de diferentes conflitos envolvendo o campesinato. No entanto, seria apenas no final da década de 1940 que os documentos do partido passariam a indicar de forma mais incisiva a necessidade de uma intervenção mais sistemática no campo. Em 1949, Grabois elaboraria as diretrizes políticas para o campo (Priori, 2003, p. 64).

Amazonas viajou a Praga para o IX Congresso do Partido Comunista da Tchecoslováquia em 1949. Durante a clandestinidade em São Paulo, Amazonas foi morar junto com a companheira, Ediria Carneiro, militante do partido, que conhecera poucos anos antes, quando ela trabalhava com Grabois como ilustradora no jornal A Classe Operária.

Por não ser dirigente do partido, Elza Monnerat não precisou entrar para a clandestinidade. Passou a atuar, com outros colegas do trabalho, na reorganização do Comitê Distrital do Centro do Distrito Federal, fechado com a cassação do partido. Monnerat integrou a Comissão de Finanças do comitê regional do Rio de Janeiro e, em 1949, no aniversário de setenta anos de Stalin, Elza - praticante de montanhismo e membro do Centro Excursionista Brasileiro - escalou o Morro Dois Irmãos com um grupo de montanhistas membros e simpatizantes do partido para pichar o nome do líder soviético. 
O "Manifesto de Agosto de 1950" viria apresentar um programa político de ruptura com as estratégias do partido. Sobre ele, Grabois escreveria:

O programa do manifesto de Prestes é um programa político preciso que deixa claro para as massas o único caminho que lhes resta para solucionar os seus problemas fundamentais - o caminho revolucionário - pois estabelece a completa independência nacional e amplas medidas democráticas que uma vez postas em prática serão capazes de assegurar a independência política e econômica do país (Grabois, 1950).

O objetivo central do programa seria, segundo Grabois, "a derrubada da atual ditadura feudal burguesa, serviçal do imperialismo, e sua substituição por um governo revolucionário", que fosse "democrático popular", "emanado diretamente do povo e legítimo representante do bloco de todas as classes e camadas sociais", "onde o proletariado seja a força dirigente". Grabois observava a existência de "condições objetivas [internas e externas] para a rápida vitória do Programa". Para tanto, os comunistas deveriam levar o programa às massas, "dirigindo-as e orientando-as" (Grabois, 1950).

Enquanto o partido radicalizava sua linha política, em outubro 1950, ordens de prisão foram emitidas contra militantes comunistas, dentre eles, Grabois e Amazonas. Em dezembro, Vargas foi eleito presidente da República.

Naquele ano, nasceu a primeira filha de João Amazonas e Ediria Carneiro e, em 1953, o segundo filho. Poucos meses depois do nascimento de João Carlos, Amazonas viajou para a União Soviética, onde passaria dois anos. A Ediria, caberia cuidar dos filhos. Durante a ausência de Amazonas, Ediria se tornaria professora do curso Stalin ministrado pelo partido, cargo que deixaria depois, por exigência de Amazonas. Além da passagem pela URSS, seu período de clandestinidade foi marcado por intensa atividade política.

Em agosto de 1954, Café Filho assumiu a presidência após a morte de Vargas. Embora o IV Congresso, realizado em novembro daquele ano, tenha ratificado a linha política do Manifesto de Agosto e continuasse defendendo a derrubada do governo, o suicídio de Vargas mudou o cenário político nacional. 


\section{A ruptura}

Em 1956, Grabois chefiou a delegação brasileira que participou do XX Congresso do Partido Comunista (PCUS) na União Soviética. Lá ficaria até o final do ano seguinte, estudando na Universidade de Moscou. Em janeiro daquele ano, Juscelino Kubitschek assumira a presidência do Brasil. Foi um período de maiores liberdades para os comunistas; embora o partido continuasse proibido, seus dirigentes deixaram a clandestinidade. A candidatura de JK havia sido apoiada pelo PCB, e João Amazonas se reunira pessoalmente com o então candidato para negociar o apoio. Não obstante a formulação de críticas às políticas internas e externas do novo governo, o PCB apoiava sua política de desenvolvimento do capitalismo nacional, ainda entendido como etapa necessária da revolução brasileira (Priori, 2003, p. 116).

Após as denúncias de Nikita Khrushchov sobre os crimes de Stalin contra seus opositores e a crítica ao culto à personalidade no XX Congresso do PCUS de 1956, Amazonas viajou mais uma vez para a União Soviética. Enquanto esteve fora, nasceu sua terceira filha.

Com a Declaração de Março de 1958, o PCB fez uma crítica às suas posições "esquerdistas" do início da década. A opção pela via pacífica seria confirmada no V Congresso do partido realizado em 1960. Grabois, Amazonas e outros membros do Comitê Central divergiam da nova posição do partido. Em Duas concepções, duas orientações políticas, Grabois afirmava que a Declaração de Março de 1958 "defende uma linha oportunista de direita" e "embeleza o capitalismo". Trata-se de um documento fundamental para entender a subsequente ruptura na cúpula do PCB, que levará à formação do PCdoB, e também para iluminar as concepções políticas levadas adiante pelo futuro comandante da Guerrilha do Araguaia. Grabois afirmava então:

Embora, na presente situação do mundo, se deva ter em conta a viabilidade do caminho pacífico, não se pode, nas condições brasileiras, torná-lo absoluto. Os comunistas preferem este caminho. Mas cometeriam grave erro se nele 
apoiassem toda a sua atuação porque nada ainda tem comprovado que o caminho da revolução brasileira é o caminho pacífico. A experiência passada e recente dos países da América Latina mostra que não foi pacífico o caminho para derrubar as ditaduras (Grabois, 1983[1960]).

Em 1961, a chamada Carta dos 100, criticando os rumos recentes do partido, levou à expulsão de seus principais signatários. Naquele ano, como estratégia para a sua legalização, o Partido Comunista do Brasil passou a se chamar Partido Comunista Brasileiro. O nome original foi adotado pelo grupo dissidente na fundação do PCdoB em fevereiro de 1962. Elza Monnerat, Maurício Grabois e João Amazonas foram eleitos para o Comitê Central do PCdoB. Os dois primeiros trabalharam no jornal A Classe Operária, periódico que vinha sendo publicado de forma intermitente pelo PCB desde 1925 e que foi assumido pelo PCdoB. Grabois era o diretor, e Monnerat, revisora; divisão de tarefas bastante representativa da divisão sexual do trabalho naquela geração de militantes.

Embora os partidos comunistas não desfrutassem de legalidade plena, pois impedidos de disputar eleições, seus militantes puderam deixar a clandestinidade. Após a ruptura com o PCB, dirigentes do PCdoB viajaram à Rússia em busca de apoio. Em maio de 1962, Grabois e Amazonas viajaram a Cuba. E, em março de 1963, Amazonas foi recebido na China por Mao Tsé-Tung.

Entre 1962 e o golpe de estado em 1964, o PCdoB se mostrava crítico ao alcance das reformas propostas por João Goulart e ao próprio governo, que ambicionava derrubar. Críticas que aumentaram em intensidade com a volta ao regime presidencialista, após o referendo para o qual o partido defendeu a abstenção dos eleitores (Sales, 2001).

\section{O golpe de 1964 e a Guerrilha do Araguaia}

Após a concretização do golpe em 1964, “a esquerda brasileira converteu-se, em pouco tempo, num mosaico de dezenas de pequenas 
organizações políticas" (Ridenti, 2014, p. 33), muitas das quais aderiram à luta armada.

Com a violenta perseguição contra comunistas e militantes de organizações sociais desde os primeiros dias do golpe, os que conseguiram escapar caíram na clandestinidade. Foi o caso de Maurício Grabois e João Amazonas. O primeiro se refugiou na casa de Elza Monnerat, que passou a alugar imóveis para esconder os dirigentes do partido. Em julho de 1964, Grabois, sua família e Amazonas foram morar juntos em São Paulo. Em 1965, Monnerat viajou para a China, mas seu pedido de emissão do passaporte chamou a atenção de autoridades policiais, que encontraram informações sobre sua militância nas décadas anteriores. Em 1966, perseguida e obrigada a deixar o emprego, a militante acabou também empurrada para a clandestinidade.

O golpe foi avaliado pelo PCdoB como um sinal de fraqueza das classes dominantes e da ingerência do governo dos Estados Unidos; o Comitê Central percebia, a partir de então, condições mais favoráveis para o desencadeamento da luta armada (Pomar, 1980). Embora os planos para a implantação de guerrilhas existissem, e, antes de 1964, militantes do partido já estivessem sendo treinados na China, tratava-se de um projeto ainda embrionário. Apenas em 1966 o partido enviaria o primeiro militante para a região escolhida para a luta armada. Grabois e Monnerat chegariam em dezembro de 1967. Acompanharam Maurício seu filho André e seu genro Gilberto Olímpio Maria, casado com Victória, que, grávida, ficou clandestina com sua mãe Alzira em São Paulo.

$\mathrm{Na}$ avaliação do PCdoB, o isolamento da região do Bico do Papagaio e seu difícil acesso possibilitariam a organização da guerrilha sem despertar maiores suspeitas e serviriam de obstáculo para a ação das forças repressivas. A quase ausência de representantes do estado permitia que os militantes treinassem em segredo, e a exploração da população local - por grileiros, madeireiros e castanheiros - gerava tensões e conflitos que poderiam servir de combustível para a expansão da luta armada. 
A estratégia de implantação na região adotada pelo partido favoreceu a aproximação de seus membros com a população local. Os militantes criaram laços com seus vizinhos, participando das atividades religiosas locais, dos mutirões e todos os tipos de interações cotidianas. Elza Monnerat apontou a importância dos ensinamentos da população da região:

Com os camponeses do Araguaia, aprendemos praticamente tudo que se referia à região onde passaríamos a viver: conhecemos cada tipo de fruta e sua época de maturação; os animais que comiam cada tipo de fruta ou coco e seus hábitos, como caçar, pescar; como carpir mato com o facão, fazer farinha, governar canoa, construir casas com cobertura e paredes de babaçu, ficar na espera etc. ${ }^{7}$

Enquanto os comunistas tocavam suas roças e pequenos comércios, realizavam igualmente treinamentos físicos e militares e aprendiam a sobreviver na floresta. A assistência médica que prestavam aos camponeses ainda é lembrada na região.

A guerrilha estava em preparação quando foi deflagrada pelo ataque das forças estatais em abril de 1972. Avisados pela população da chegada do exército, os guerrilheiros se embrenharam na mata. A ajuda dos camponeses com informação, abrigo e alimentação foi fundamental para a sobrevivência dos comunistas nas primeiras fases da luta armada (Campos Filho, 2012).

Iniciava-se um período de terror na região; a violência das forças da ditadura foi indiscriminada. Centenas de camponeses foram presos e torturados, suas casas e plantações foram queimadas. Indígenas Aikewara tiveram suas terras ocupadas pelos militares e foram obrigados, assim como alguns camponeses, a guiá-los pela mata. Todos esses crimes cometidos por agentes do estado deixaram marcas profundas na região e nos sobreviventes, e continuam impunes (Comissão Nacional da Verdade, 2014).

Em abril de 1972, Monnerat, que entrava e saía da região com frequência, dada sua função de apoio à guerrilha, voltava ao Pará quando

${ }^{7}$ Entrevista realizada para a edição de 1996 do documento Guerrilha do Araguaia. Uma epopeia pela liberdade, publicado pela editora Anita Garibaldi. 
descobriu o cerco militar. Conseguiu avisar Amazonas, que também estava a caminho da área.

Depois de três campanhas militares, a guerrilha foi totalmente derrotada. A Comissão Militar da guerrilha foi atacada no Natal de 1973, desde então, não se tem mais notícias sobre Maurício Grabois, que permanece desaparecido.

Além de Elza Monnerat e João Amazonas, sobreviveram apenas uns poucos militantes presos nas fases iniciais dos combates e dois que escaparam da região durante a última campanha militar; os demais foram assassinados - geralmente depois de detidos - e ainda estão desaparecidos. ${ }^{8}$

De volta a São Paulo, Monnerat continuaria a militar no PCdoB. Tinha um papel fundamental, era responsável pela organização dos encontros entre os membros do Comitê Central em São Paulo até a sua prisão em 1976. Nesse momento, quando os dirigentes do partido foram presos ou assassinados, Amazonas se encontrava fora do Brasil, iniciando um exílio que terminaria só em 1979, com a Lei de Anistia, que levaria igualmente à liberação de Monnerat. Atuante no PCdoB até a sua morte, em 2004, Monnerat deixou para o partido seu pequeno apartamento no bairro do Catete, no qual viveu quase toda a sua vida e que, em muitos momentos, servira de esconderijo para militantes comunistas. Já Amazonas se tornou a voz mais importante do PCdoB, ocupando sua presidência até 2001, um ano antes de sua morte.

\section{Características das trajetórias}

O caminho de transição do PCB para o PCdoB aparece na trajetória de diferentes militantes que participaram da construção da luta armada na região do Bico do Papagaio. Além de Grabois, Amazonas e Monnerat, Francisco Amaro Lins, Ângelo Arroyo e Francisco Chaves completam uma geração de militantes que se filiou ao PCB nos anos 1930 e 1940 e que

${ }^{8}$ À exceção de Maria Lúcia Petit e Bergson Gurjão Farias, cujas ossadas foram encontradas e identificadas. 
foram deslocados para o Araguaia. Quase não existem informações sobre a vida de Francisco Manoel Chaves, um dos poucos militantes negros que participou da Guerrilha do Araguaia. Sabe-se que Chaves nasceu em 1906, era marinheiro e foi preso por participar do levante da ANL (Luiz, 2018). Amaro Lins nasceu em 1920, era operário no Rio de Janeiro, casado e tinha filhos. Já Arroyo nasceu em 1928, era operário em São Paulo, também casado e com filhos e, assim como Monnerat, entrara no partido em seu momento de maior efervescência, em 1945.

Apesar das diferenças nas biografias dos militantes, é possível encontrar traços comuns nessas trajetórias. Em primeiro lugar, são os militantes mais velhos deslocados para a região da guerrilha. Eles compartilharam uma longa trajetória militante, na qual foram socializados com as interpretações comunistas sobre a realidade brasileira e com as ideias de transformação da ordem hegemônica. É importante, portanto, para o sentido da luta armada dessa geração de militantes, o fato de que a perspectiva revolucionária por meio das armas esteve no horizonte do Partido Comunista Brasileiro em diferentes momentos da sua história. Além de presente nos programas do partido e nos discursos de seus dirigentes, como Maurício Grabois, essa perspectiva teórica tomava forma também por meio de ações, como durante a participação no levante organizado pela ANL nos anos trinta, na participação do partido em conflitos armados ao lado de camponeses, em Trombas e Formoso e Porecatu, no final da década de 1940 e início da seguinte, ou ainda no envio de militantes para treinamento na China na década de 1960.

Ainda que a presença de comunistas mais velhos na guerrilha do Araguaia tenha sido minoritária, ela revela a existência de diferentes trajetórias que levaram ao engajamento no movimento, tendo em vista que esses militantes foram socializados politicamente em contextos históricos distintos e influenciados de forma diversa pelos eventos políticos que compartilharam em suas trajetórias. Por exemplo, para um militante que já era membro de alguma organização política de esquerda e teve que entrar na clandestinidade com o golpe, o Ato Institucional no 5 (AI-5) não teve 
o mesmo impacto em sua trajetória de engajamento na luta armada que um ativista que, até dezembro de 1968, militava no movimento estudantil.

As mudanças ocorridas no interior da organização à qual pertenciam foram igualmente importantes na construção do sentido da opção pela luta armada nas trajetórias analisadas; visto que a razão reivindicada pelos dissidentes para a criação do PCdoB (ou reorganização, como preferem chamar seus militantes) estava no que consideravam uma postura reformista por parte do PCB a partir finais da década de 1950.

A situação de ilegalidade do partido comunista durante quase todo o século XX, a perseguição de seus militantes e a interrupção violenta de seu breve funcionamento legal em 1947 são fundamentais na construção da luta armada como uma opção legítima no contexto brasileiro. É possível observar, na reconstrução das três trajetórias, um processo gradual de engajamento iniciado em formas mais seguras de ativismo (McAdam, 1986; della Porta, 1995). A clandestinidade imposta pela repressão estatal aos militantes é um elemento central nessas trajetórias.

Como lembra Della Porta (1995), ao privar os agentes de outros laços, a clandestinidade reforça aqueles criados no interior da organização. Se, no começo das trajetórias, redes criadas em espaços de trabalho e lazer ocuparam um lugar importante na construção da sociabilidade do militante, progressivamente, em função das demandas da militância ou da clandestinidade, as redes relevantes para os agentes passam a ser o partido e a família, principalmente para os que tinham outros parentes no partido. A clandestinidade limita o surgimento de laços concorrentes e ajuda a definir a opção pela luta armada. Além de um sentimento de solidariedade geral e da convicção na justeza - e na viabilidade - da luta política, a solidariedade com outros membros da organização é uma das explicações para a manutenção do engajamento em um contexto de grande risco à vida.

Se tomarmos em conta apenas responsabilidades familiares, a disponibilidade biográfica não foi um fator decisivo para o engajamento dos militantes homens, que eram casados e tinham filhos, diferente de 
Monnerat. Vale notar que as esposas de Grabois e Amazonas pertenciam ao PCdoB e não participaram da guerrilha. Com efeito, o engajamento de mulheres implicava na superação de barreiras criadas em diferentes esferas sociais - família, religião, trabalho, escola - pelo aparato repressivo estatal e dentro dos próprios grupos políticos dos quais faziam parte (Teles, 2014, p. 13). Dentre os 78 militantes enviados pelo PCdoB para preparar o movimento armado no sudeste do Pará, estavam apenas 19 mulheres.

É possível pensar também que, para Grabois e Amazonas, o casamento com militantes do partido facilitava o engajamento na medida em que diminui a possível resistência de laços sociais centrais para os agentes (McAdam; Paulsen, 1993). Ademais, a presença na luta armada de André Grabois e Gilberto Olímpio, filho e cunhado de Maurício Grabois, indicam outro tipo de impacto dos laços sociais fortes na participação no movimento.

Finalmente, importa sublinhar que, se a identidade militante é construída ao longo da trajetória dos agentes, ela é definida igualmente pelo contexto político presente, o que explica que, embora o significado da luta armada tenha sido construído ao longo da biografia dos militantes aqui apresentados, o engajamento em um movimento com essas características se deu na ditadura civil-militar, um regime especialmente fechado e violento contra seus opositores.

\section{Considerações finais}

Se, na reconstrução de trajetórias militantes, é preciso levar a sério o papel das ideologias em voga, como recomendam Fillieule et al. (2018), certamente influenciaram a escolha dos militantes aqui apresentados, a difusão de ideias e experiências comunistas revolucionárias no cenário internacional. Essas "vitrines da utopia realizada" (Reis Filho, 1990, p. 94) e a leitura do contexto político nacional indicavam uma crise da dominação capitalista e a viabilidade de uma guerrilha rural no país. Contudo, para esses militantes comunistas de longa data, o sentido da opção pela luta armada foi construído ao longo de suas trajetórias. Partir das trajetórias militantes para 
entender o engajamento na guerrilha nos possibilita situá-lo no contexto de uma militância anterior. Por meio das trajetórias, foi possível indicar igualmente o pertencimento dos militantes a redes organizacionais (do partido, do trabalho) e informais (familiares, de amigos) que, relacionadas a uma forte identificação com uma identidade militante comunista, foram necessárias para o engajamento.

Para quem tinha uma longa militância no comunismo, o golpe militar deixava poucas alternativas. Ao empurrar esses militantes para clandestinidade e ao indicar uma crise do sistema político e do regime capitalista - segundo a interpretação compartilhada por parte importante dos comunistas na época -, o golpe de 64 aparece como uma oportunidade para desencadear a luta armada - opção legitimada pela violenta repressão aos opositores do regime, pelas ideias comunistas revolucionárias com as quais os militantes foram socializados ao longo do século $\mathrm{XX}$, pelas redes sociais nas quais os agentes estavam imersos, pelas disponibilidades biográficas e pelas experiências individuais de perseguição.

Rafaela N. Pannain é Doutora em Sociologia e pesquisadora do Centro Brasileiro de Análise e Planejamento. $\bowtie$ rafaelapannain@hotmail.com

\section{Referências}

1. AGRIKOLIANSKY, Éric. Carrières militantes et vocation à la morale : les militants de la LDH dans les années 1980. Revue française de science politique, v. 51, n. 1-2, p. 27-46, 2001. https://doi.org/10.3917/rfsp.511.0027

2. ALMEIDA, Paul. Multi-sectoral coalitions and popular movement participation. Research in Social Movements, Conflicts and Change, v. 26, p. 65-99, 2005. http://dx.doi.org/10.1016/S0163-786X(05)26003-2

3. BERCHT, Verônica. Coração Vermelho: a vida de Elza Monnerat. São Paulo: Fundação Maurício Grabois, Editora Anita Garibaldi, 2013.

4. BERTOLINO, Osvaldo. Maurício Grabois: uma vida de combates. São Paulo: Fundação Maurício Grabois, Editora Anita Garibaldi, 2012. 
5. BOSI, Lorenzo; DELLA PORTA, Donatella. Micro-mobilization into armed groups: Ideological, instrumental and solidaristic paths. Qualitative Sociology Review, v. 35, p. 361-383, 2012. https://doi.org/10.1007/s11133-012-9237-1

6. BUONICORE, Augusto. Meu verbo é lutar: a vida e o pensamento de João Amazonas. São Paulo: Fundação Maurício Grabois, Editora Anita Garibaldi, 2012.

7. CAMPOS FILHO, Romualdo P. A Guerrilha do Araguaia: a esquerda em armas. São Paulo: Fundação Maurício Grabois, Editora Anita Garibaldi, 2012.

8. COMISSÃO NACIONAL DA VERDADE. Relatório Final, v. II, 2014.

9. DELLA PORTA, Donatella. Social movements, political violence and the state. A comparative analysis of Italy and Germany. Cambridge: Cambridge University Press, 1995.

10. DORIA, Palmério et al. A guerrilha do Araguaia. São Paulo: Alfa Omega, 1979.

11. FILLIEULE, Olivier. Some elements of an interactionist approach to political disengagement. Social Movements Studies, v. 9, n. 1, p 1-15, jan. 2010. https://doi.org/10.1080/14742830903442436

12. FILLIEULE, Olivier et al. Changer le monde changer sa vie. Enquête sur les militantes et les militants des années 1968 en France. Arles: Actes Sud, 2018.

13. GORENDER, Jacob. Combate nas trevas. A esquerda brasileira: das ilusões perdidas à luta armada. São Paulo: Editora Ática, 1987.

14. GOULD, Roger. Multiple networks and mobilization in the Paris Commune, 1871. American Sociological Review, v. 56, n. 6, p. 716-729, dez. 1991. https://doi.org/10.2307/2096251

15. GRABOIS, Maurício. Discurso pronunciado na Câmara dos Deputados na sessão de 7 de janeiro de 1948, em que foi aprovado o projeto da cassação dos mandatos. Problemas - Revista Mensal de Cultura Política, n. 7, fev. 1948. Disponível em: https://www.marxists.org/portugues/grabois/1948/01/cassacao.htm.

16. GRABOIS, Maurício. Mobilizar grandes massas para defender a paz e derrotar o imperialismo e a ditadura. Problemas - Revista Mensal de Cultura Política, n. 20, ago./set. 1949. Disponível em: https://www.marxists.org/portugues/ grabois/1949/05/mobilizar.htm.

17. GRABOIS, Maurício. Programa da Frente Democrática de Libertação Nacional. Um Poderoso Instrumento de Luta. Problemas - Revista Mensal de Cultura Política, n. 29, ago./set. 1950. Disponível em: https://www.marxists.org/ portugues/grabois/1950/09/programa.htm.

18. GRABOIS, Maurício. Duas concepções, duas orientações políticas. Revista Princípios, n. 6, jun. 1983 [1960]. Disponível em: https://www.marxists.org/ portugues/grabois/1960/mes/duas.htm.

19. GRABOIS, Victória L. Maurício Grabois: meu Pai. Rio de Janeiro: Editora Hexis, 2012. 
20. LUIZ, Janailson M. Notas sobre a clandestinidade: Francisco Manoel Chaves e a participação negra nas mobilizações comunistas no Brasil. Lutas Sociais, v. 22, n. 40, p. 94-107, 2018. https://doi.org/10.23925/ls.v22i40.46676

21. McADAM, Doug. Recruitment to high-risk activism: The case of freedom summer. American Journal of Sociology, v. 92, n. 1, p. 64-90, jul. 1986. https://doi.org/10.1086/228463

22. McADAM, Doug; PAULSEN, Ronnelle. Specifying the relationship between social ties and activism. American Journal of Sociology, v. 99, n. 3, p. 640-667, nov. 1993. https://doi.org/10.1086/230319

23. MORAIS, Taís; SILVA, Eumano. Operação Araguaia: os arquivos secretos da guerrilha. São Paulo: Geração Editorial, 2011.

24. PAGIS, Julie. Les incidences biographiques du militantisme em Mai 68. Une enquete sur deux générations familiales : des "soixante-huitards" et leurs enfants scolarisés dans deux écoles expérimentales. 2009. Tese (Doutorado em Sociologia) - École des Hautes Études en Sciences Sociales, Paris, 2009.

25. POMAR, Wladimir. Araguaia o partido e a guerrilha. São Paulo: Brasil Debates, 1980.

26. PRESTES, Anita L. 70 anos da Aliança Nacional Libertadora (ANL). Estudos Ibero-Americanos, v. 31, n. 1, p. 101-120, jun. 2005. https://doi. org/10.15448/1980-864X.2005.1.1328

27. PRIORI, Angelo. O PCB e a questão agrária: os manifestos e o debate político acerca dos seus temas. In: MAZZEO, Antonio Carlos; LAGOA, Maria Izabel (org.). Corações Vermelhos: os comunistas brasileiros no século XX. São Paulo: Editora Cortez, 2003. p. 61-82.

28. REIS FILHO, Daniel A. A revolução faltou ao encontro: os comunistas no Brasil. São Paulo: Editora Brasiliense, 1990.

29. RIDENTI, Marcelo. As oposições à ditadura: resistência e integração. In: REIS FILHO, Daniel A.; RIDENTI, Marcelo; MOTTA, Rodrigo P. S. (org.). A ditadura que mudou o Brasil: 50 anos do golpe de 1964. Rio de Janeiro: Jorge Zahar, 2014. p. 30-47.

30. RIDENTI, Marcelo. O Fantasma da revolução brasileira. São Paulo: Unesp, 2010 [1993].

31. SALES, Jean R. O Partido Comunista do Brasil nos anos sessenta: estruturação orgânica e atuação política. Cadernos AEL, v. 8, n. 14/15, p. 16-48, 2001.

32. SALGADO, Maria M. Recrutamento em movimentos de alto risco: o caso da Frente Sandinista de Libertação Nacional (FSLN). 2015. 178 f. Dissertação (Mestrado em Sociologia) - Faculdade de Filosofia, Letras e Ciências Humanas, Universidade de São Paulo, São Paulo, 2015.

33. SANTOS, Leonardo S. Do que "os Livros Diziam" à Rua da Glória, n. 52: o PCB e a "questão camponesa" (1927-1947). Revista IDeAS, v. 3, n. 2, p. 389-424, jul./dez. 2009. 
34. TELES, Maria Amélia de A. O protagonismo de mulheres na luta contra a ditadura militar. Revista Interdisciplinar de Direitos Humanos, v. 2, n. 2, p. 9-18, jun. 2014.

35. VITERNA, Jocelyn. Pulled, pushed, and persuaded: Explaining women's mobilization into the Salvadoran guerrilla army. American Journal of Sociology, v. 112, n. 1, p. 1-45, jul. 2006. http://dx.doi.org/10.1086/502690

Recebido em: 20 ago. 2020.

Aceito em: 26 jan. 2021. 